\title{
Electrospun cotton-wool-like silica/gelatin hybrids with covalent coupling
}

\author{
Maria Nelson $\mathbb{1}^{1} \cdot$ Francesca Tallia $\mathbb{D}^{1} \cdot$ Samuel J. Page $\mathbb{C}^{2} \cdot$ John V. Hanna $\mathbb{D}^{2} \cdot$ Yuki Fujita ${ }^{3} \cdot$ Akiko Obata $\mathbb{D}^{3} \cdot$ \\ Toshihiro Kasuga $\mathbb{D}^{3} \cdot$ Julian R. Jones $\mathbb{D}^{1}$
}

Received: 7 June 2020 / Accepted: 3 October 2020 / Published online: 21 October 2020

(C) The Author(s) 2020

\begin{abstract}
Inorganic/organic sol-gel hybrids consist of co-networks of inorganic and organic components that can lead to unique properties, compared to conventional composites, especially when there is covalent bonding between the networks. The aim here was to develop new electrospun silica/gelatin sol-gel hybrids, with covalent coupling and unique 3D cotton-wool-like morphology for application as regenerative medicine scaffolds. Covalent coupling is critical for obtaining sustained dissolution of the fibres and we identified the sol-gel synthesis conditions needed for coupling within the electrospun fibres. Under carefully controlled conditions, such as constant humidity, we investigated the effect of the electrospinning process variables of sol viscosity (and aging time) and amount of coupling agent on the 3D morphology of the fibres, their structure (bonding) and dissolution, identifying a detailed optimised protocol for fibre scaffold production.
\end{abstract}

\section{Graphical Abstract}

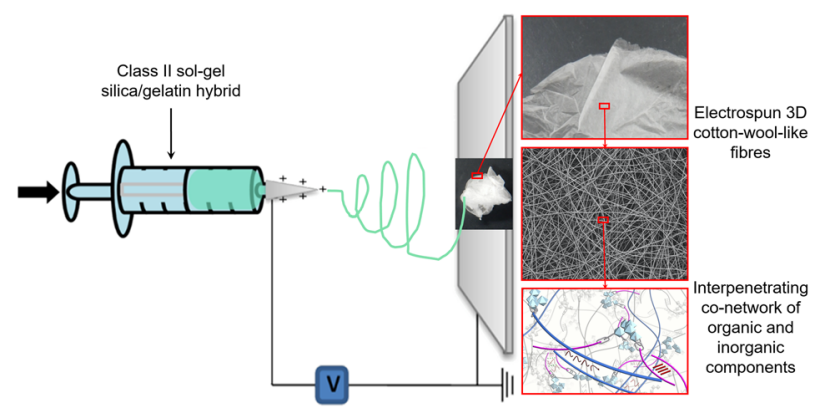

Keywords Inorganic/organic hybrid $\cdot$ Type-II hybrid $\cdot$ Silica/gelatin $\cdot$ Electrospinning

Francesca Tallia

f.tallia@imperial.ac.uk

$₫$ Julian R. Jones

julian.r.jones@imperial.ac.uk

1 Department of Materials, Imperial College London, South Kensington Campus, London SW7 2AZ, UK

2 Department of Physics, University of Warwick, Gibbet Hill Road, Coventry CV4 7AL, UK

3 Graduate School of Engineering, Nagoya Institute of Technology, Gokiso-cho, Showa-ku, Nagoya 466-8555, Japan 


\section{Highlights}

- Silica/gelatin sol-gel hybrids were electrospun with covalent coupling between the silica and gelatin networks.

- Processing parameters were optimised to give homogeneous fibre diameters and 3D architecture.

- NMR, TGA, and dissolution studies gave evidence successful coupling.

- Increasing the covalent coupling increased the spinnability of the fibres.

- Covalent coupling gave control of the dissolution rate of the fibres.

\section{Introduction}

Inorganic/organic sol-gel hybrids are being applied to regenerative medicine strategies as traditional materials have not been able to fulfil all the design requirements of scaffolds [1]. The criteria are that the scaffold should: be biocompatible (not toxic); provide a temporary 3D template (scaffold) for cell migration and production of new tissue, without the formation of fibrous encapsulation (bioactivity); match the mechanical properties (e.g. stiffness) and mimic the environment (e.g., extracellular matrix) of the host tissue; biodegrade at a controlled rate as the tissue regrows; be sterilisable and be able to be manufactured to Good Manufacturing Practice (GMP) [1]. For bone regeneration, bioactive glasses have been shown to regenerate bone faster than other bioactive ceramics [2], but they are stiff and brittle. Even so, spun bioactive glasses fibres have been applied in wound healing applications, as a scaffold that fills the wound, with a dressing placed over the top of the wound [3, 4], reducing healing times [5-7]. A borate-based bioactive glass formed into cotton-like fibres, MIRRAGEN (ETS Woundcare, Rolla, MO), recently attained FDA approval for healing of diabetic ulcers.

Conventional composites can have controlled stiffness and elastomeric properties [8], but when glass or ceramic particles are dispersed within a polymer matrix, they can be masked by the polymer. Sol-gel hybrids, made by adding an organic polymer into the sol before it gels, have the potential to overcome these problems due to the molecular scale interactions between the inorganic and organic components, which translate to controlled degradation rate. Covalent bonding between components has been achieved through the use of coupling agents such as isocyanatopropyl triethoxysilane $[9,10]$ and glycidoxypropyl trimethoxysilane (GPTMS) [11]. For the polymer source, synthetic polymers have been used $[9,12]$, but natural polymers have the advantage of degrading under the action of enzymes, which should give a more sustained degradation rate in vivo, compared to the rapid autocatalytic degradation of synthetic polyesters [13]. During hybrid synthesis, the organic polymer is usually functionalised with the coupling agent before it is introduced to the sol, e.g., a polymer containing nucleophilic groups, such as carboxylic acid groups, can be functionalised with GPTMS as the nucleophilic groups open the epoxy ring [14]. The functionalised polymer then has side chains with alkoysilane groups and it is added to the sol-gel process, forming covalent bonds between $\mathrm{Si}-\mathrm{OH}$ bonds from the hydrolysed coupling agent and the silica network in the sol, forming a class-II hybrid [15]. Gelatin has high potential in silica/gelatin hybrid materials [16-18], as it is an analogue of collagen, making it a mimic of the composition of natural extracellular matrix. Other crosslinking agents for gelatin include genipin [19] and gluteraldahyde [20] but they do not bond to the silica network.

Poly $(\gamma$-glutamic acid) is also a useful natural polymer source, as it can be synthesised by bacteria fermentation route and it is a mimic of collagen, which contains glutamic acid units [21]. Class-II silica/poly( $\gamma$-glutamic acid) hybrids were developed, using GPTMS as the coupling agent [22-25], but poly( $\gamma$-glutamic acid) is difficult to obtain. Chitosan is a popular polymer for hybrid synthesis, as it can be extracted from seafood waste [26-28], but it is difficult to determine whether the GPTMS coupling agent bonds with the chitosan [11, 29].

Initially, hybrid scaffolds were produced by the sol-gel foaming technique [30], including the silica/gelatin system $[31,32]$, wherein the use of GPTMS was shown to enable congruent dissolution of the inorganic and organic components. More recently, sol-gel hybrids have been 3D printed to produce grid-like scaffolds that perform well under cyclic loads, in the silica/gelatin system [33], albeit in a class-I hybrid (no covalent bonding between the co-networks), and from synthetic polymers [34]. Printing the hybrid with a specific pore size provoked chondrocytes to produce collagen type-II matrix [34], typical of articular cartilage matrix, and stem cells to differentiate down a chondrogenic route [35].

Electrospinning is commonly used as a strategy for producing scaffolds that can mimic the architecture of the extracellular matrix of articular cartilage [36-38]. It applies an electric field between a needle, that delivers a solution, and a collector. It can be applied to the sol-gel process, even hybrid sols [39, 40]. Usually, electrospinning produces 2D nonwoven fibre mats [38], but for many applications a 3D scaffold is needed, to fill a large space and to allow cell migration. Previously, we have shown that sol-gel derived bioactive glasses can be produced in a 3D format [41], if conditions, such as humidity, are carefully controlled [42]. This was extended to poly(L-lactide)/vaterite systems [43, 44] and to 
poly( $\gamma$-glutamic acid)/silica hybrid sols [45]. While silica/ gelatin hybrids have been electrospun [46, 47], they were produced in 2D fibremat morphology. Previous electrospun class-II silica/gelatin sol-gel hybrids were developed for bone repair [46], and so contained calcium and phosphate for bioactive apatite layer formation on immersion in body fluid. The degree of covalent coupling is expected to have been low as dissolution studies in phosphate-buffered saline solution resulted in significant fusion and webbing of the fibres after only $12 \mathrm{~h}$. This is because covalent bonding between the gelatin and the GPTMS was unlikely as the GPTMS was introduced to the sol at a $\mathrm{pH}$ of 3.1, which has since been found to spontaneously open the epoxide ring of the GPTMS [48], by hydrolysis, forming a diol and preventing bonding to the gelatin by nucleophilic reaction $[11,14]$. Low $\mathrm{pH}$ may also cause degradation of the gelatin [49]. The aim here was to electrospin a silica/gelatin hybrid while ensuring covalent coupling for sustained biodegradation. 3D electrospun scaffolds with fibres that mimic the dimensions of collagen fibres of extracellular matrix could be used as flexible devices for: filling chronic wounds and non-loading bone defects or cartilage regeneration.

Here, we show the first electrospinning of class-II silica/ gelatin sol-gel hybrids in a cotton-wool-like 3D morphology. Design of the sol for electrospinning is critical for success. A high degree of coupling was chosen to ensure that the high surface area fibres did not degrade rapidly. Functionalisation of the gelatin was performed under optimised $\mathrm{pH}$ conditions (4.4) to ensure bonding of the GPTMS
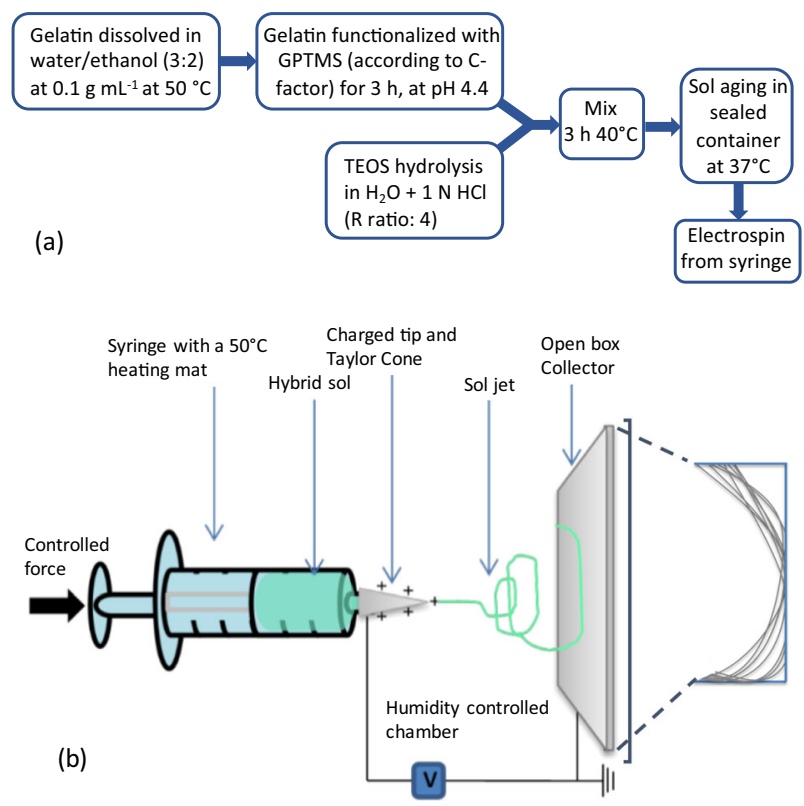

Fig. 1 Synthesis and electrospinning apparatus: a flow diagram of the synthesis method for electrospinning silica-gelatin hybrids; aging time, electrospinning conditions and drying conditions were investigated; b schematic of the electrospinning apparatus to the gelatin. Process variables such as solvent choice, solution viscosity, electrical field and separation between tip and collector were investigated.

\section{Materials and methods}

\subsection{Hybrid synthesis and electrospinning parameters}

All reagents were sourced from Sigma-Aldrich (UK), unless stated otherwise. The starting protocol was gelatin (Type A porcine, 'gel strength 300') dissolved in an ethanol/water $(40: 60 \% \mathrm{v} / \mathrm{v})$ solution at a concentration of $0.1 \mathrm{~g} \mathrm{~mL}^{-1}$, maintaining the $\mathrm{pH}$ at 4.4 by the addition of $1-\mathrm{M} \mathrm{HCl}$, stirring at $400 \mathrm{rpm}$. The procedure and other variables are summarised in Fig. 1. Adding ethanol to water increases volatility and lowers conductivity, gelatin solubility and gelation temperature [50, 51]. Lower conductivity leads to higher net charge density, which favours formation of thinner fibres [50, 51].

Functionalisation of gelatin was performed by adding the appropriate amount of GPTMS. The degree of the covalent coupling between the gelatin and the silicate network is key tool for controlling degradation rate and mechanical properties of the hybrid and can be termed the coupling factor ('C-factor') [31, 32]. C-factor is the molar ratio of GPTMS to gelatin, assuming a molecular weight of gelatin of $87.5 \mathrm{kDa}$ [32]. Hybrid sols were produced with a molar ratio of gelatin to tetraethyl orthosilicate (TEOS) of 70:30. The silica sol was prepared separately with hydrolysis of TEOS started $1 \mathrm{~h}$ before the end of gelatin functionalisation by mixing reagents in the following order: deionized water, 1-M HCl and TEOS. The R-ratio (molar ratio of water: TEOS) was 4 and the volume ratio of water/ $\mathrm{HCl}$ was 3 . The solution was stirred for $1 \mathrm{~h}$ at $400 \mathrm{rpm}$ to allow hydrolysis of TEOS. The functionalised gelatin and hydrolysed TEOS were mixed and returned to the hot plate at $40{ }^{\circ} \mathrm{C}$ at $400 \mathrm{rpm}$. After $3 \mathrm{~h}$ of solution aging on a hot plate, the hybrid solutions were transferred to a sealed container and into a $37^{\circ} \mathrm{C}$ oven, where solution aging resumed.

Once solution aging was complete, the hybrid reached the 'electrospinning viscosity range', the viscosity range within which the hybrid solution could be electrospun to form distinct, fused fibres. The required solution-aging time and 'electrospinning viscosity range' was dependent on the other variables being investigated. After electrospinning, the $3 \mathrm{D}$ scaffolds were left to dry over night at room temperature, $25^{\circ} \mathrm{C}$.

The effect of $\mathrm{C}$-factor, aging time, electrospinning conditions, viscosity, tip-collector separation and applied voltage on the structures generated by electrospinning was investigated. 
Previously, Gao et al. [46] dissolved gelatin in acetic acid/ water, prior to addition of the bioactive glass sol-gel precursor sol. GPTMS was added after $2 \mathrm{~h}$, at $\mathrm{pH} 3$, to give a hypothetical C-factor of 370 , and stirred for $4 \mathrm{~h}$ before electrospinning, although from the manner of degradation of the hybrid, it seems coupling did not occur. For example, for Cfactor 500 , for $3.9 \mathrm{~g}$ of gelatin solubilised, in the ethanol/ water, $3.90 \mathrm{ml}$ of GPTMS was added. The composition used herein as a starting point was $70 \mathrm{G}$ CF185, corresponding to $70 \%$ gelatin and a C-factor of 185 , which was chosen based on work by Song et al. [52], who investigated the electrospinning of gelatin and GTPMS alone (no TEOS), in acetic acid, and found that a C-factor of 185 (1:2 w/w ratio of GPTMS:gelatin) formed smooth discrete nanofibers, while above a C-factor of 370 the fibres fused together.

A transparent poly(methylmethacrylate) chamber containing desiccant silica beads was placed around the needle and collector plate to limit the humidity to $55 \%$ (Fig. 1b). Humidity affects fibre diameter by influencing the rate of solvent evaporation: at higher humidity, reduced rate of solvent evaporation allows the jet to continue to elongate towards the collector, and smaller fibres are observed. Increasing humidity also causes greater bending of electrospun fibres which was found to increase the 3D nature of electrospun sol-gel scaffolds, with $55 \%$ being optimal [42]. At higher humidity, beading can occur as the surface area increases and charge per unit area becomes unstable [53].

To ensure that the hybrid sol remained above the gelation temperature of gelatin, prior to delivery, a heat mat was wrapped around the delivery syringe, set at $50{ }^{\circ} \mathrm{C}$. A stainless steel $18-8$ hypodermic 5 cc needle was used and, flow rate was $0.05 \mathrm{~mL} \mathrm{~min}^{-1}$, delivered by a horizontal syringe pump (FP-W-100, Melquest, Japan).

To form 3D cotton-wool fibres from the silica-gelatin hybrids, the fibre elongation effects of high humidity will be investigated here, and to ensure fibres do not fuse together, a box-like collector was used, which allows fibres to dry without coming into contact with each other. Fibres that came into contact when suspended formed the 3D fusion structure.

To monitor how this evolution of viscosity affected electrospinning, the $70 \mathrm{G}$ CF185 electrospinning study aimed to determine:

(1) The solution viscosity dependence on time of $70 \mathrm{G}$ CF185 solution compared to $100 \mathrm{G}$ CF185 solutions (no TEOS);

(2) The viscosity range compatible with electrospinning;

(3) The needle-collector distance required for successful electrospinning at each viscosity;

(4) The applied voltage required for successful electrospinning at each viscosity.

\subsection{Viscosity-voltage relationship}

It was important to determine how the viscosity of the sol increased with aging time (h) and what viscosity was most appropriate for electrospinning. The rheological behaviour was therefore mapped and the effect of increasing viscosity on fibre formation examined. For each viscosity, the effect of increasing voltage was also studied to find the most appropriate conditions for electrospinning this hybrid sol.

Two compositions were compared: $70 \mathrm{G}$ CF185 and 100G CF185 (no TEOS). For the 70G composition, hybrids were prepared as shown in Fig. 1 and after $1 \mathrm{~h}$ of mixing the functionalised gelatin with hydrolysed TEOS, solutions were further aged in a $37^{\circ} \mathrm{C}$ oven. The solution aging time begins as soon as the two components are mixed, or for the $100 \mathrm{G}$ samples, simply at the end of the $3 \mathrm{~h}$ functionalisation stage. During this period of aging, 3-mL samples were removed at 1-h intervals, and placed in a $5-\mathrm{mL}$ syringe warmed to $50{ }^{\circ} \mathrm{C}$. The viscosity of the solution was measured, and the solutions were electrospun at three voltages: $7,9.5$ and $12 \mathrm{kV}$. These values were selected after initial experiments showed $5 \mathrm{kV}$ to be too low to induce fibre formation and $15 \mathrm{kV}$ to be too high. All electrospinning was completed within $20 \mathrm{~min}$ to minimise effects of viscosity increase within the time point. The separation between needle and collector plate was investigated (between 15 and $20 \mathrm{~cm}$ ) for each voltage at each time point. This experiment was repeated for another $100 \mathrm{G}$ composition with $\mathrm{C}$-factor of 500 .

\subsection{Composition compatibility study}

Increasing the $\mathrm{C}$-factor in the hybrid composition was expected to increase the degree of crosslinking in the network and reduce the dissolution rate of the fibres. The objective here was to investigate the effect on increasing $\mathrm{C}$-factor on the viscosity increase over the solution aging time; the viscosity range for fibre generation; and the types of structures achievable.

The compositions analysed were all $70 \mathrm{G}$ with C-factors of 250,500 and 750 . The synthesis method follows the method in Fig. 1. The sol aging stage consisted of $3 \mathrm{~h}$ stirring on a hot plate. Sols were then separated into 12-mL batches and frozen. These batches were later aged in the oven at $37^{\circ} \mathrm{C}$ when ready for testing.

After a minimum of $1 \mathrm{~h}$ in the oven, the viscosities of the solutions were measured and samples were electrospun for $30 \mathrm{~min}$ with a voltage of $9.5 \mathrm{kV}$ and a needlecollector separation of $20 \mathrm{~cm}$. This process was repeated until solutions were too viscous for electrospinning. 


\subsection{Characterisation techniques}

Viscosity of the hybrid sols was measured with an Anton Paar Modular Compact Rheometer, MCR 102, with a solvent trap, at $40^{\circ} \mathrm{C}$, taking 50 points at 2-s intervals at a frequency of $20 \mathrm{~s}^{-1}$. The average viscosity was calculated and standard deviations were negligible.

Scanning electron microscopy (SEM) imaging was carried out on osmium-coated (Neoc Meiwafosis, Japan) samples under secondary ion imaging, using a JCM 600, JEOL SEM operating at $5 \mathrm{kV}$ with a working distance of $20 \mathrm{~cm}$. Fibre diameters were measured using ImageJ (25 fibres per image).

All Fourier-transform infrared (FTIR) analysis was done using FT/IR-4100, JASCO with ATR PR0450-S stage. All spectra were normalised to the gelatin amide I peak at $1640 \mathrm{~cm}^{-1}$. Thermal gravimetric analysis (TGA) was performed using a Netzsch STA $449 \mathrm{C}$ from 21 to $800^{\circ} \mathrm{C}$ at a ramp rate of $10 \mathrm{~K} \mathrm{~min}^{-1}$ with an air flow rate $50 \mathrm{~mL} \mathrm{~min}^{-1}$ in a platinum crucible $(n=3)$.

The ${ }^{29} \mathrm{Si}$ MAS NMR data were acquired at $14.1 \mathrm{~T}$ using a JEOL JNM EAC-600 spectrometer operating at a Larmor frequency of $119.2 \mathrm{MHz}$. These measurements were performed using a JEOL 7-mm HX probe, which enabled a MAS frequency of $6 \mathrm{kHz}$ to be implemented throughout. Quantitative measurements were obtained using ${ }^{29} \mathrm{Si}$ single pulse (direct excitation) experiments. A ${ }^{29} \mathrm{Si} \pi / 2$ pulse time of $5.5 \mu$ s being calibrated on solid kaolinite, with a $\pi / 6$ pulse time of $\sim 1.8 \mu$ s and a 20 -s recycle delay employed for each measurement. All ${ }^{29} \mathrm{Si}$ chemical shifts were reported against the IUPAC recommended primary reference of $\mathrm{Me}_{4} \mathrm{Si}(1 \%$ in $\mathrm{CDCl}_{3}, \delta 0.0 \mathrm{ppm}$ ), via a kaolinite secondary (solid) reference shift at $-92.0 \mathrm{ppm}$ [54]. The relative peak areas were resolved by deconvolution using OriginPro software, and the network condensation $\left(D_{c}\right)$ was calculated using Eq. (1) $[22]:$

$D_{c}=\left(\left[\frac{4 Q^{4}+3 Q^{3}+2 Q^{2}}{4}\right]+\left[\frac{3 T^{3}+2 T^{2}+T^{1}}{3}\right]\right) \times 100 \%$,

where $Q^{n}$ is the abundance of $Q^{n}$ species and $T^{n}$ is the abundance of $T^{n}$ species. A $Q^{n}$ species consists of a $\mathrm{Si}$ atom with $n$ bridging oxygen ( $-\mathrm{Si}-\mathrm{O}-\mathrm{Si}-$ ) bonds and 4- $n$ nonbridging oxygen bonds. A $T^{n}$ species consists of a $\mathrm{Si}$ atom with one $\mathrm{Si}-\mathrm{C}$ bond and $n$ bridging oxygen $(-\mathrm{Si}-\mathrm{O}-\mathrm{Si}-)$ bonds and 3- $n$ non-bridging oxygen bonds.

Dissolution of the hybrid fibres was investigated by immersion of $15 \mathrm{mg}$ of the fibres in $10 \mathrm{~mL}$ of TRIS buffer solution for 1 week, as per the recommended conditions for bioactive glass testing in simulated body fluids [55]. Silicon concentration in TRIS was measured using inductive couple plasma (ICP, ICPS - 7510, Shimadzu, Japan) analysis and gelatin was quantified using a Pierce bovine serum albumin (BCA) Protein Assay kit. Time points were: 1, 2, 4, 8, 24, 48, 72 and $168 \mathrm{~h}$. At each time point $0.7 \mathrm{~mL}$ was removed for ICP, centrifuged to avoid fibres entering test samples, and $0.5 \mathrm{~mL}$ of the spun down solution was added to $9.5 \mathrm{~mL}$ of DI water and $25 \mu \mathrm{L}(n=3)$ was removed for the BCA assay in 96 microwell plates. Additional time points at 96 and $120 \mathrm{~h}$ were added for the BCA assay. All removed solution was replaced with fresh TRIS solution and the $\mathrm{pH}$ was monitored. BCA standards were produced using 1-mg $\mathrm{mL}^{-1}$ gelatin solution. The assay is less sensitive to gelatin than the protein it is designed to work with, albumin, so to lower the minimum detection range of the assay the microplate incubation time was increased to $4 \mathrm{~h}$.

\section{Results and discussion}

The aim was to produce scaffolds with morphology of 3D cotton-wool (or cotton candy) with discrete fibres, that extend in all directions, with diameters of $\sim 1 \mu \mathrm{m}$, that would also remain stable after immersion in buffer for more than 1 week. This definition of 3D electrospun scaffold is distinct from some literature definitions which define ' $3 D$ ' as $2 D$ fibre mats, which are simply thicker (e.g., $\sim 0.5-2 \mathrm{~mm}$ ) than conventional '2D' non-woven fibre mats $(<0.5 \mathrm{~mm})$ [56].

The viscosity of the sol strongly affects the fibre formation, with low viscosity resulting in droplets and at high viscosity the jet does not eject from the syringe. The gelatin to silica ratio and solvent choice (surface tension) are known to affect the viscosity [57], with high surface tension causing jet instability (electrospraying) [58], but here these factors were kept constant, although a TEOS-free sol was also studied. Optimum viscosity of the class-II hybrid sol was determined through controlling gelation time and the

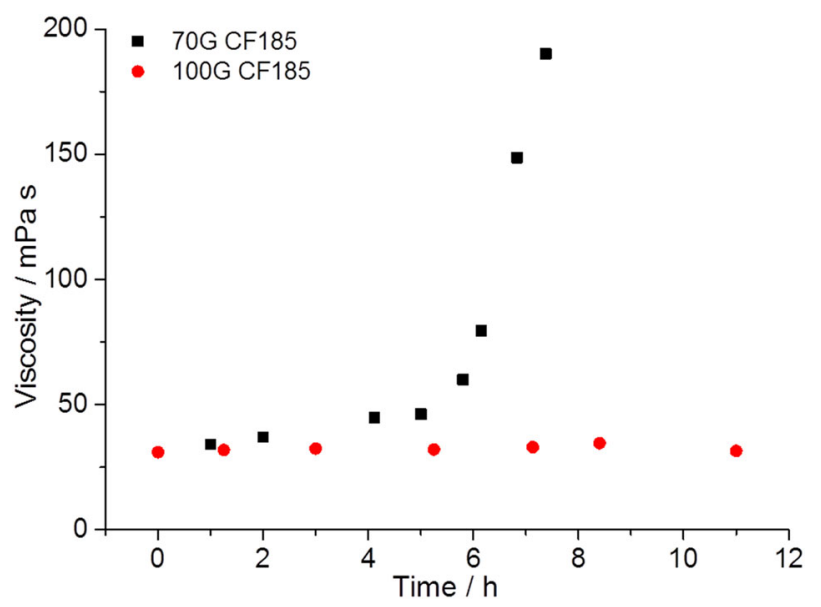

Fig. 2 Viscosity measurements over solution aging time for CF185 (Cfactor 185) hybrid sols with (70G, 70\% gelatin) and without TEOS (100G) 
Fig. 3 SEM images representative of electrospun 70G CF185 silica/gelatin hybrid: a-g fibres electrospun at 7 and $9.5 \mathrm{kV}$ spun at sol viscosities of: a, b $37 \mathrm{mPa} \mathrm{s}$; c, d $46 \mathrm{mPa} \mathrm{s}$; e, f $60 \mathrm{mPa}$ and $\mathbf{g} 79 \mathrm{mPas}$. Scale bars: a, c, e, g $50 \mu \mathrm{m}$; b, d, f $5 \mu \mathrm{m}$

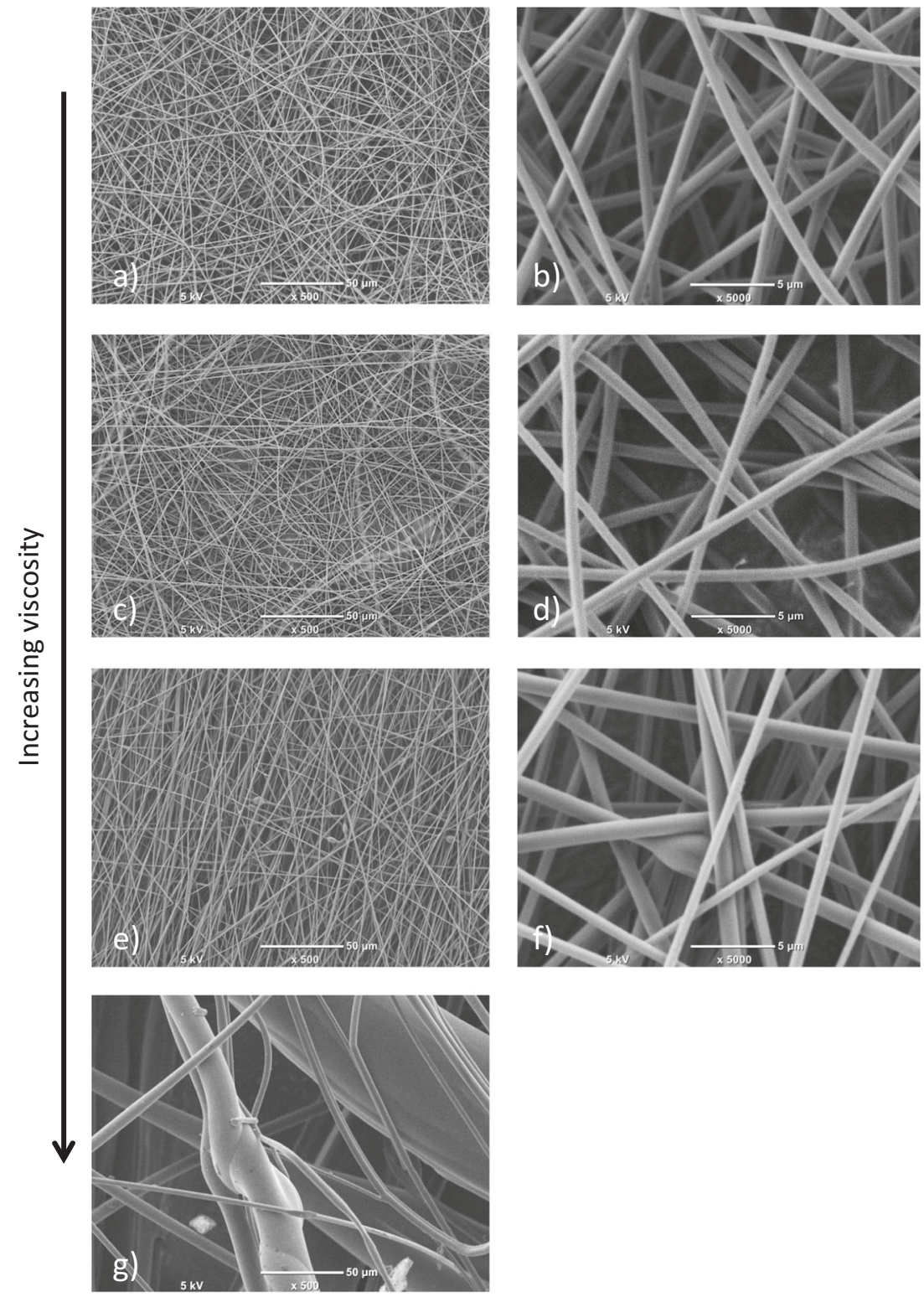

C-factor, which determines $D_{c}$. Successful spinning was defined as continuous fibre formation from needle to collector, and fibres were distinct, i.e., they were not fused together at the collector (identified by SEM).

\subsection{Viscosity-voltage study}

Competition between electric field, surface tension and viscoelastic force dictates whether smooth fibres or beads form. The surface tension drives to reduce surface energy by forming narrow fibre jets [59], however below a certain viscosity, beaded fibres can form.

The viscosity of the silica-gelatin hybrid sols increased as gelation/aging time increased (Fig. 2), due to gelation of the silicate network and crosslinking of the Si-GPTMSgelatin network during solution aging. The change in
Table 1 Mean fibre diameters and standard deviations in $\mu \mathrm{m}$ of $70 \mathrm{G}$ CF185 fibres electrospun at increasing viscosities and voltages

\begin{tabular}{lll}
\hline Viscosity/mPa s & Applied voltage $/ \mathrm{kV}$ & Fibre diameters $/ \mu \mathrm{m}$ \\
\hline 37 & 9.5 & $0.75 \pm 0.12$ \\
46 & 9.5 & $0.79 \pm 0.10$ \\
60 & 9.5 & $0.81 \pm 0.21$ \\
79 & 9.5 & $8.5 \pm 6.4$ \\
$40-60$ & 12 & $1.5 \pm 0.5$ \\
\hline
\end{tabular}

viscosity over time for $100 \mathrm{G}$ CF185 (no TEOS) and 70G CF185 solutions was markedly different. Within a solution aging period of $8 \mathrm{~h}$, the viscosity of the $70 \mathrm{G} \mathrm{CF} 185$ solution increased from 34 to $190 \mathrm{mPas}$, whereas the $100 \mathrm{G}$ CF185 solution remained around $33 \pm 2 \mathrm{mPas}$. This is expected, as for GPTMS to crosslink gelatin alone, GPTMS 
molecules that are bonded to gelatin must come into contact with each other to form a Si-O-Si bridge between gelatin molecules, whereas the silicate network provided by TEOS can expedite the gelation.

The 70G CF185 sols were spun within the viscosity range of 37-79 $\mathrm{mPa}$ at different voltages: 7, 9.5 and $12 \mathrm{kV}$. The applied voltage must overcome the forces of surface tension, however above this critical point, the effects of higher voltages depend on the solution. Higher voltages cause increased volume of ejected sol, producing thicker fibres, whereas others have reported narrowing of the fibres due increased electrostatic charges and greater stretching of the solution [57].

Here, fibres produced from $70 \mathrm{G}$ CF185 sol at 7 and $9.5 \mathrm{kV}$ had similar structure and fibre diameter at all viscosities tested (Fig. 3). Fibres spun with viscosity in the range of $37-60 \mathrm{mPas}$ were similar, with diameters $0.7-0.8 \mu \mathrm{m}$ (Fig. 3a-f and Table 1). At $60 \mathrm{mPas}$, the standard deviation of the fibre diameters approximately doubled, to $\pm 0.21 \mu \mathrm{m}$, and some beading was observed (Fig. 3f). As viscosity increased to $79 \mathrm{mPa} \mathrm{s}$, the fibres were much thicker and wirey with high fibre diameter variation; $8.5 \pm 6.4 \mu \mathrm{m}$ (Fig. $3 \mathrm{~g}$ ). The $79 \mathrm{mPa}$ s fibres are visible to the naked eye, and spinning was problematic as gelling occurred at the nozzle frequently and fibres were released in bursts.

Increasing the applied voltage to $12 \mathrm{kV}$ was detrimental to fibre formation, causing fusion and larger fibre diameters (Fig. 4 and Table 1). The higher voltage increased the speed of the fibre jets and prevented total evaporation of the solvent before reaching the collector plate. Viscosity therefore had a much more significant role in fibre formation than the voltage applied. The optimal viscosity range of $37-60 \mathrm{mPa}$ $\mathrm{s}$ was lower than those of synthetic polymers such as polyethylene oxide (527-1835 $\mathrm{mPa}$ ) [51], due to the presence of the inorganic in the sol.

The separation between needle and plate was adjusted to achieve continuous flow of fibres to allow fibres to dry before reaching the collector [60]. The optimum distance for CF185 fibres with viscosity values between 37 and $60 \mathrm{mPa}$ s was $20 \mathrm{~cm}$ while using 7 and $9.5 \mathrm{kV}$ applied voltage. To achieve (semi)continuous flow at $79 \mathrm{mPa}$ s and to electrospin at $12 \mathrm{kV}$, the distance had to be increased to $30 \mathrm{~cm}$. At smaller separations than $15 \mathrm{~cm}$, continuous fibre formation was not possible due to erratic bursts of fibres leading to voltage drops. At higher separations, fibres did not reach the collector.

The SEM images (Fig. 3) show that stable fibres formed when sol was electrospun when it had viscosity within the initial, linear region of the viscosity-time relationship (Fig. 2). As viscosity increased past $60 \mathrm{mPa}$, the viscosity rose at a significantly increased rate and the fibres formed had a poor and inconsistent structure. Attempts to electrospin the $100 \mathrm{G}$ CF185 solution did not result in any fibre formation within the first $11 \mathrm{~h}$ of aging, with the viscosity of the sol having a mean value of $33 \mathrm{mPa}$. A voltage of $7 \mathrm{kV}$ did not produce a jet, whereas 9.5 and $12 \mathrm{kV}$ resulted in electrospraying. Increasing the $\mathrm{C}$-factor of $100 \mathrm{G}$ did not help.

Figure 5 shows FTIR spectra of the $70 \mathrm{G}$ CF185 fibres electrospun with increasing solution viscosities. Changes in vibration bands can be attributed to changes in $D_{c}$. Bands at 2870, 1200, 910 and $850 \mathrm{~cm}^{-1}$ are all attributed to GPTMS methoxy, Si-C bond, epoxy (oxirane and GPTMS Si-OH) and methyl groups, respectively. Bands at 1040 and $790 \mathrm{~cm}^{-1}$ correspond to the $\mathrm{Si}-\mathrm{O}-\mathrm{Si}$ asymmetric and symmetric vibrations, respectively. Bands at $3300 \mathrm{~cm}^{-1}$ (N-H amide A), $2930 \mathrm{~cm}^{-1}$ (C-H amide B), $1640 \mathrm{~cm}^{-1}$ (Amide I), $1540 \mathrm{~cm}^{-1}$ (Amide II), $1450 \mathrm{~cm}^{-1}$ (Amide III) are all attributed to gelatin. The band at $958 \mathrm{~cm}^{-1}$ was assigned to asymmetric stretching of Si-OH from hydrolysed TEOS which was not fully condensed. The spectra were normalised to Amide I.

As the viscosity of the solutions increased, the asymmetric $\mathrm{Si}-\mathrm{O}-\mathrm{Si}$ band intensity relative to the amide bands decreased and the Si-OH (from TEOS) band, and oxirane + $\mathrm{Si}-\mathrm{OH}$ (from GPTMS) band increased relative to the amide bands, suggesting the $\mathrm{Si}-\mathrm{O}-\mathrm{Si}$ content reduced while $\mathrm{Si}$ $\mathrm{OH}$ contributions increased in the fibres as the viscosity of the sols increased.

The optimal applied voltage for electrospinning $70 \mathrm{G}$ CF185 was therefore $9.5 \mathrm{kV}$ for a sol in the ideal range $37-46 \mathrm{mPas}$, producing fibres of diameter of $\sim 0.8 \mu \mathrm{m}$, which were thicker than $70 \mathrm{G}$ CF185 hybrid fibres produced by Gao et al. [46] $(192 \pm 8 \mathrm{~nm})$, perhaps due to increased $D_{c}$ and different humidity (not reported). These parameters were taken forward to investigate the effect of changing the C-factor.

\subsection{The effect of C-factor}

To increase the covalent coupling, the effect of increasing C-factor to CF250, CF500 and CF750 on electrospinning was investigated by spinning at different solution aging times (viscosities). Figure 6 shows how the viscosity of the hybrid sols increased with solution aging time. The different points correspond to multiple batches. The viscosity changed in two stages: initially a slow steady increase and then a sharp increase. The gradient of this second stage appears very similar regardless of the $\mathrm{C}$-factor, however the onset time of this second stage increased as C-factor increased. It was therefore important to identify why the $\mathrm{C}$-factor affected the inflection point.

It is likely that the rapid viscosity increase is the point at which the gel network has formed to the point that it can no longer hold all the liquid phase [61]. The time taken to reach that point increased as $\mathrm{C}$-factor increased due to more 
Fig. 4 SEM images of 70G CF185 fibres representative of those spun at $12-\mathrm{kV}$ solutions from a sol aged to a viscosity of 40-60 mPa s: a low magnification; b higher magnification. Scale bars: a $50 \mu \mathrm{m} ; \mathbf{b} 5 \mu \mathrm{m}$
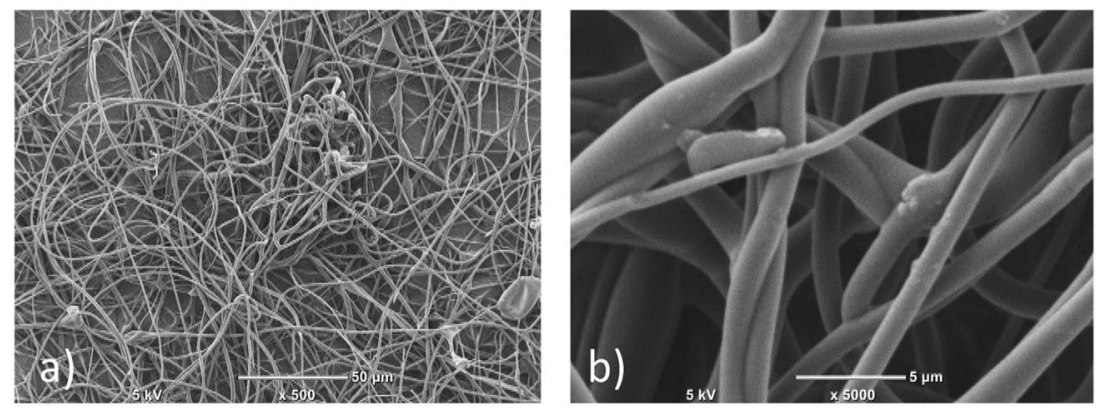

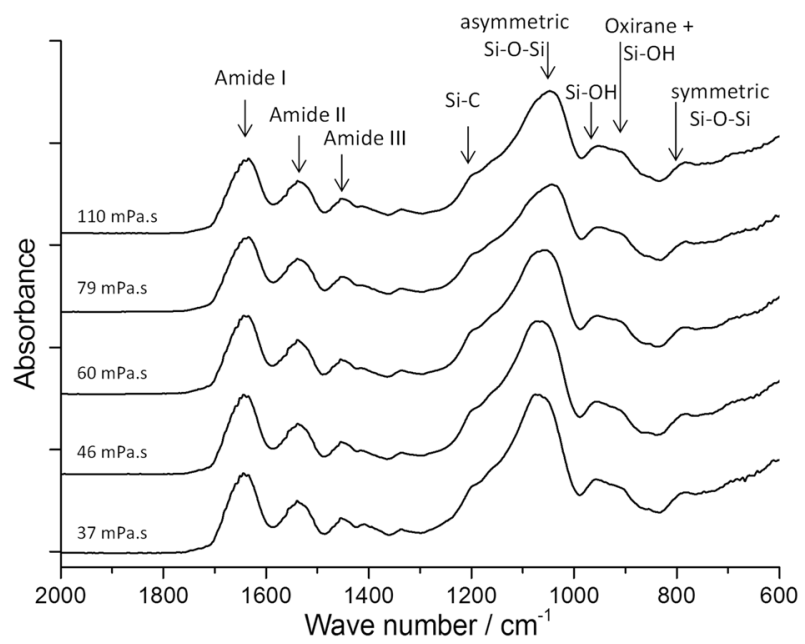

Fig. 5 FTIR of $70 \mathrm{G}$ CF185 electrospun samples spun from sol of increasing viscosity as a result of solution aging

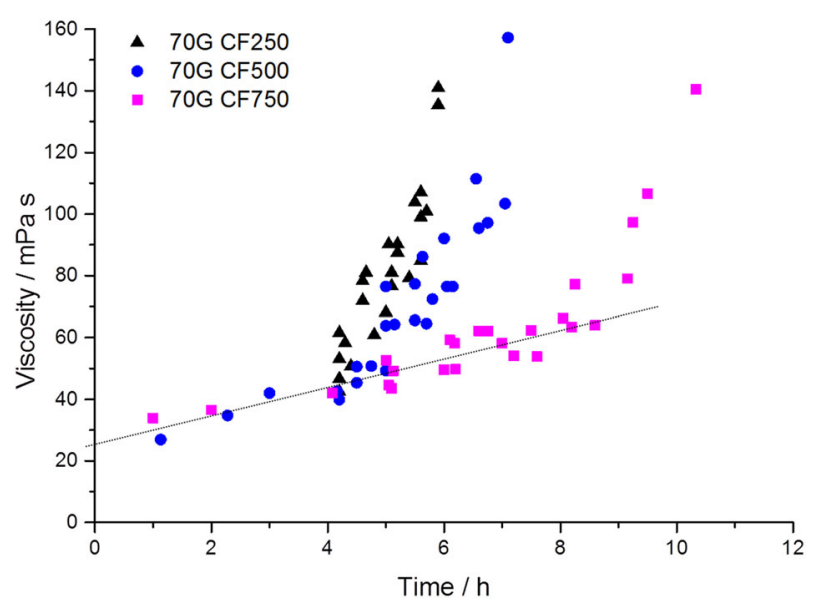

Fig. 6 Viscosity measurements for $70 \mathrm{G}$ CF250, CF500 and CF750 sols measured during electrospinning in relation to solution aging time

rapid crosslinking and shrinkage the also due to increased amount of methanol produced by GPTMS hydrolysis. At CF750, the amount of GPTMS added to gelatin was substantial $(11.47 \mathrm{~mL})$, added to $56 \mathrm{~mL}$ of gelatin solution, which would have and released $5.87 \mathrm{~mL}$ of methanol, whereas CF250 fibres released one third the amount of methanol.

Figure 7 shows SEM images of typical electrospun fibre structures produced with C-factors 250,500 and 750 , at increasing viscosities, with the fibre diameters given in Table 2. The CF250 sol produced discrete and homogeneous fibres, at all viscosities, similar to those seen for CF185 (Fig. 2). However, at viscosities of $<50 \mathrm{mPa}$ s, only CF250 formed distinct fibres, and they were in the form of 2D fibre mats, whereas CF500 and CF750 fibres fused together. 3D structures needed higher viscosity of 60-80 mPa s for CF250 and CF500 sols and $60-100 \mathrm{mPa} \mathrm{s}$ for CF750 sols. The increased fusion of fibres at higher Cfactors was attributed to the higher $D_{c}$ and increased amount of methanol by-product.

The 3D cotton-wool fibres are shown in Fig. 8. The mean fibre diameter increased to $1.35,1.51$ and $1.60 \mu \mathrm{m}$ as C-factor increased to CF250, CF500 and CF750, respectively. The formation of the 3D structure was attributed to a combination of: the high humidity [42], which allowed a slow solvent evaporation rate and highly elongated fibres to form; optimal sol viscosity; and the shape of the collector, which was an open box lined with aluminium foil lining, and enabled collection of the ejected fibres at the collector's edges, allowing gelation and drying with the fibres merging. The change in gradient in viscosity (Fig. 6) coincided with the start of cotton-wool-like hybrid formation. As CF185 solutions only formed 2D fibre mats, we can assume there is cut-off C-factor value between 185 and 250 below which the 3D cotton-wool-like formation did not have a high enough stiffness at this ratio of gelatin to silica.

Figure 9a compares FTIR spectra of 3D cotton-wool-like fibres, made from higher viscosity sol, to those of the $2 \mathrm{D}$ fibre mats (low viscosity sol). All compositions and viscosities that produced distinct fibres during electrospinning had similar relative band intensities to the amine I band: $2 \mathrm{D}$ CF250, 3D CF250, 3D CF500 and 3D CF750.

Spectra of the CF250 fibres showed no differences in the relative band intensities between $2 \mathrm{D}$ and $3 \mathrm{D}$ fibres. The relative intensities of the bands in the spectra of 3D fibres of CF500 and CF750 were similar to the 2D formed by the 


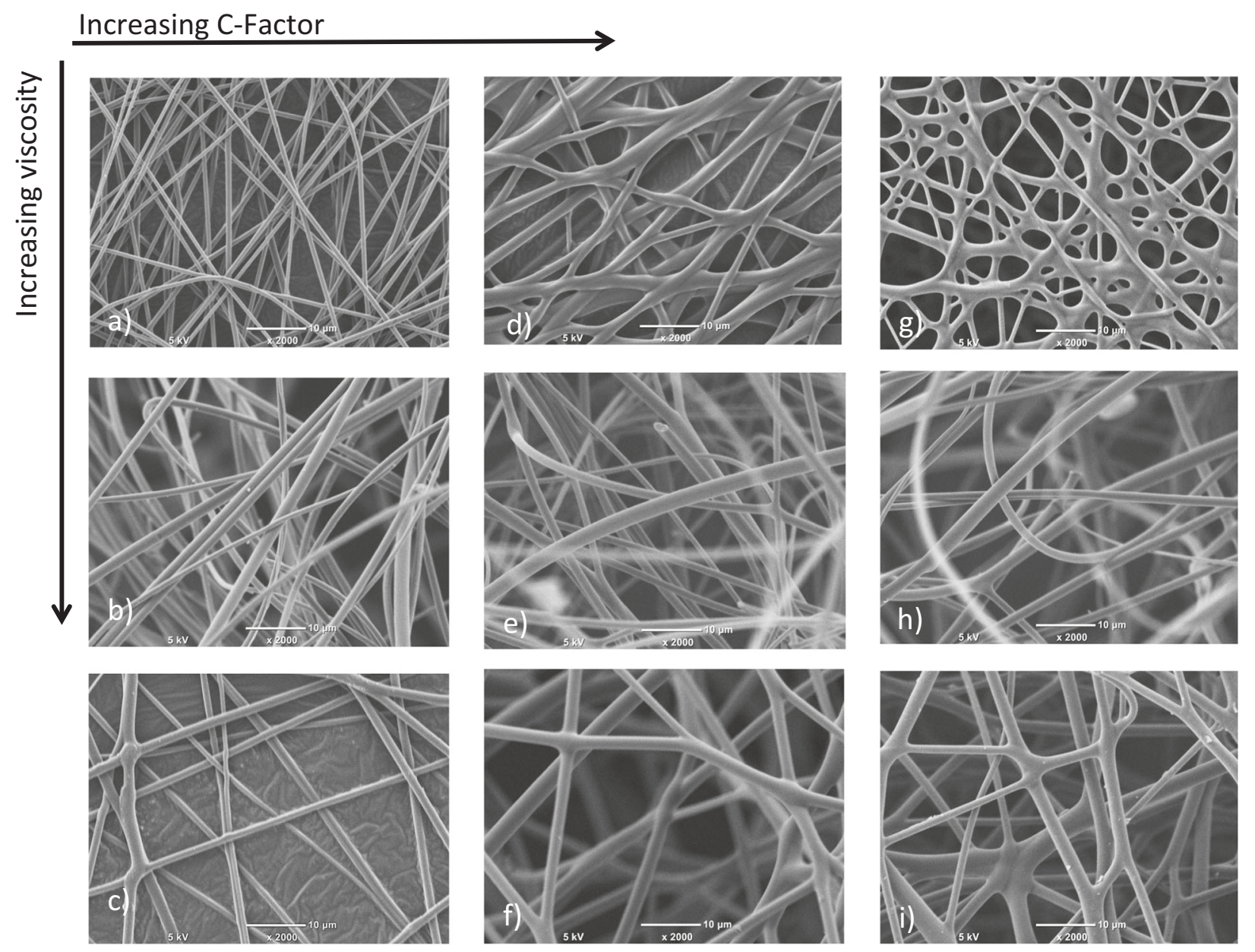

Fig. 7 SEM images of electrospun $70 \mathrm{G}$ hybrid fibres with increasing C-factor and viscosity, spun at $9.5 \mathrm{kV}$. a-c CF250; $\mathbf{d}-\mathbf{f}$ CF500 and $\mathbf{g}-\mathbf{i}$ CF750. As viscosity increased, the structures changed: a, d, $\mathbf{g} 2 \mathrm{D}$ fibre mats electrospun from viscosities of 44,45 and $49 \mathrm{mPa}$ s, respectively;

Table 2 Fibre diameters of $70 \mathrm{G}$ hybrid made with different $\mathrm{C}$-factors (CF) in the form of 2D fibre mats, 3D cotton-wool fibres and 3D fused fibres (Fig. 7)

\begin{tabular}{lccc}
\hline Type of fibre & \multicolumn{3}{l}{ Mean fibre diameters \pm standard deviation $/ \mu \mathrm{m}$} \\
\cline { 2 - 4 } & $\mathrm{CF} 250$ & $\mathrm{CF} 500$ & $\mathrm{CF750}$ \\
\hline 2D fibre mats & $0.88 \pm 0.18$ & - & - \\
3D cotton-wool & $1.35 \pm 0.51$ & $1.51 \pm 0.54$ & $1.60 \pm 0.50$ \\
3D fusion & - & $2.21 \pm 0.56$ & $2.09 \pm 0.76$ \\
\hline
\end{tabular}

CF250 fibres (with the exception of a band at $950 \mathrm{~cm}^{-1}$ in CF250). The band at $950 \mathrm{~cm}^{-1}$ was also observed in both CF185 hybrid fibre spectra and is associated with $\mathrm{Si}-\mathrm{OH}$ [46]. The $950 \mathrm{~cm}^{-1}$ band was not present in the hydrolysed GPTMS spectra (Fig. 9b), so it was assigned to Si-OH from uncondensed hydrolysed TEOS, which would have lowered the resultant connectivity of the silica network and increased the $\mathrm{Si}-\mathrm{OH}$ contribution. This corresponds to the $\mathbf{b}, \mathbf{e}, \mathbf{h}$ 3D cotton-wool-like structures electrospun from viscosities of 72, 66 and $64 \mathrm{mPa}$, respectively; c, f, i fibre fusion occurred at viscosities of 81,76 and $65 \mathrm{mPa}$, respectively. Scale bar is $10 \mu \mathrm{m}$

Table 3 Moles of GPTMS and gelatin, and C-factor, calculated from the remaining inorganic after TGA of hybrids of $70 \%$ silica, with nominal C-factors of: CF250, CF500, CF750

\begin{tabular}{lllll}
\hline $\begin{array}{lll}\text { Hybrid } \\
\text { of functionalised gelatin }\end{array}$ & $\begin{array}{l}\text { GPTMS/ } \\
\text { moles }\end{array}$ & $\begin{array}{l}\text { Gelatin/ } \\
\text { moles } \times 10^{-4}\end{array}$ & $\begin{array}{l}\text { C- } \\
\text { factor }\end{array}$ \\
\hline CF250 & 14 & 0.18 & 7.40 & 249 \\
CF500 & 21 & 0.27 & 5.48 & 492 \\
CF750 & 23 & 0.30 & 4.82 & 628 \\
\hline
\end{tabular}

ability of CF250 to form distinct fibres at low viscosities rather than fused fibre sheets as are seen for CF500 and CF750.

Both resultant spectra of the CF500 and CF750 hybrid fibres were similar, though there was a very slight increase in asymmetrical $\mathrm{Si}-\mathrm{O}-\mathrm{Si}$ for $\mathrm{CF} 750$ fibres. This implied that the amount of silica incorporated in the hybrid fibres had only marginally increased despite the $50 \%$ increase in $\mathrm{C}$-factor. 
Fig. 8 Photographs of 70G fibre structures formed with $\mathrm{C}$-factors of a 250 , b 500 and c 750 . The fibre sheets at the top represent 2D fibres formed at low viscosities. The bottom images show 3D cotton-wool structures laid out flat (middle) and as produced in their up like cotton-wool-like morphology (bottom)
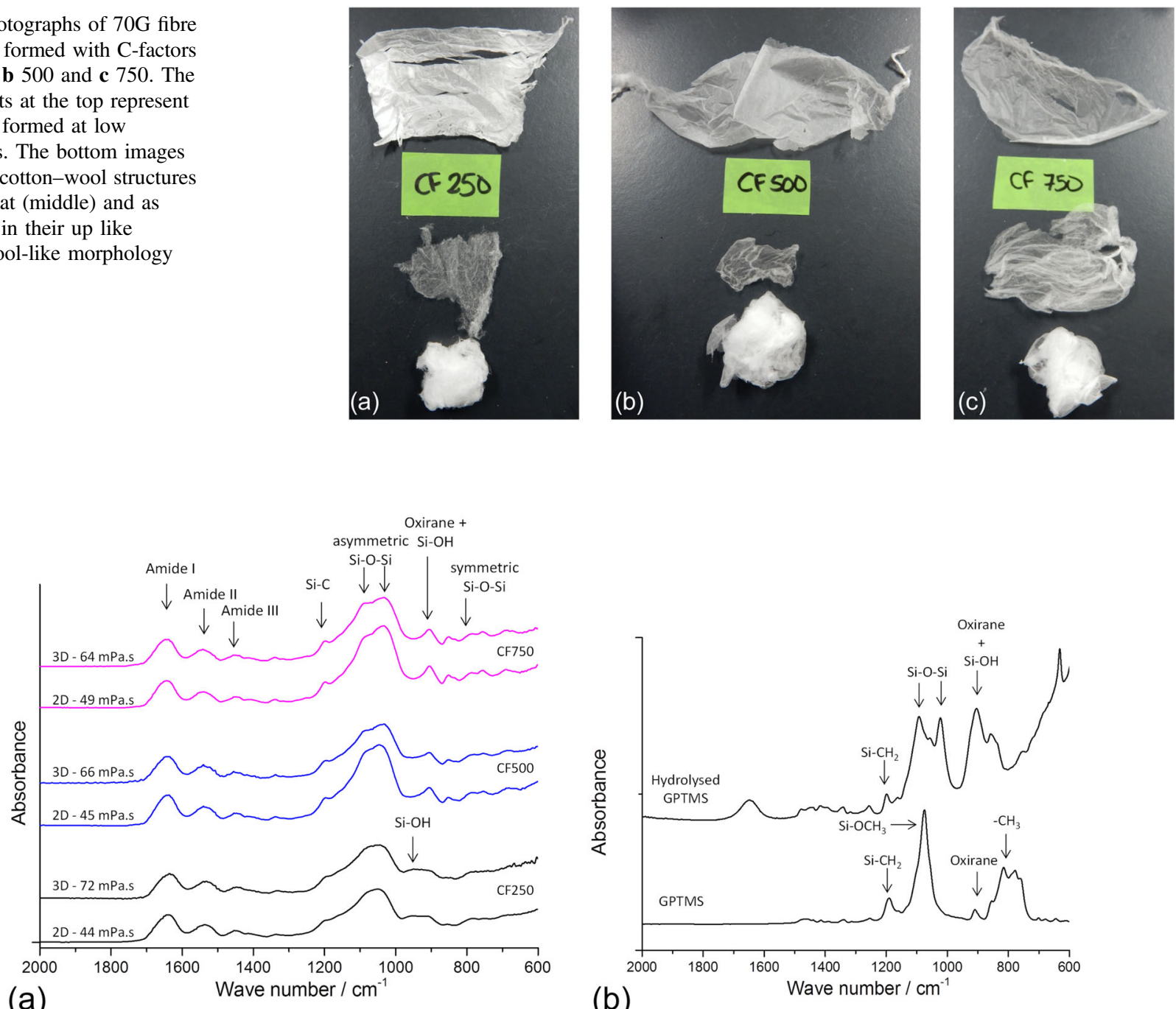

(b)

Fig. 9 FTIR spectra of: a 70G hybrid fibres with increasing C-factor produced by electrospinning comparing 3D cotton-wool fibres (60-80 mPa s) to $2 \mathrm{D}$ sheets (40-60 $\mathrm{mPa} \mathrm{s}$ ); b GPTMS as received and hydrolysed

It is also interesting that the spectrum for CF750 does not show an increased ratio of $\mathrm{Si}-\mathrm{O}-\mathrm{Si}$ to gelatin, compared to CF500. The ratio is higher for CF500 and CF750 samples compared to CF250. This implies that the amount of silica incorporated in the solution did not increase, despite the increase in GPTMS above CF500. This suggests that at CF500, the amino side groups on the gelatin, which are the GPTMS attachment sites, are saturated, so further addition of GPTMS effectively acts as an increase in solvent. This may affect the solution aging time and could be a reason for fusion of the CF500 and CF750 fibres if there is excess GPTMS.

\subsection{Investigating evidence of covalent coupling}

TGA was used to determine experimentally the percentage gelatin and $\mathrm{C}$-factor of the electrospun scaffolds. The
CF250 and CF500 samples both show C-factors very similar to the predicted value (Table 3 ), however as predicted, a C-factor of 750 was not reached. The $\mathrm{C}$-factor was actually $\sim 630$, which is still a significant increase in GPTMS inclusion over CF500.

The TGA plots showed that the percentage of organic content was 62, 68 and $67 \%(\mathrm{w} / \mathrm{w})$, for $70 \mathrm{G}$ fibres with CF250, CF500 and CF750, respectively (Fig. 10). As hydrolysed GPTMS is itself $66 \%$ organic, the fluctuation in total organic content was due to the C-factor. When electrospinning, there is opportunity for gelatin, GPTMS and hydrolysed TEOS to be lost from the final fibre composition as droplets of solution, which fall from the needle. This is typical of electrospinning and these droplets may have contained unreacted components of the solution, or excess homogeneous solution if the flow rate was too high. The former option is more likely. 


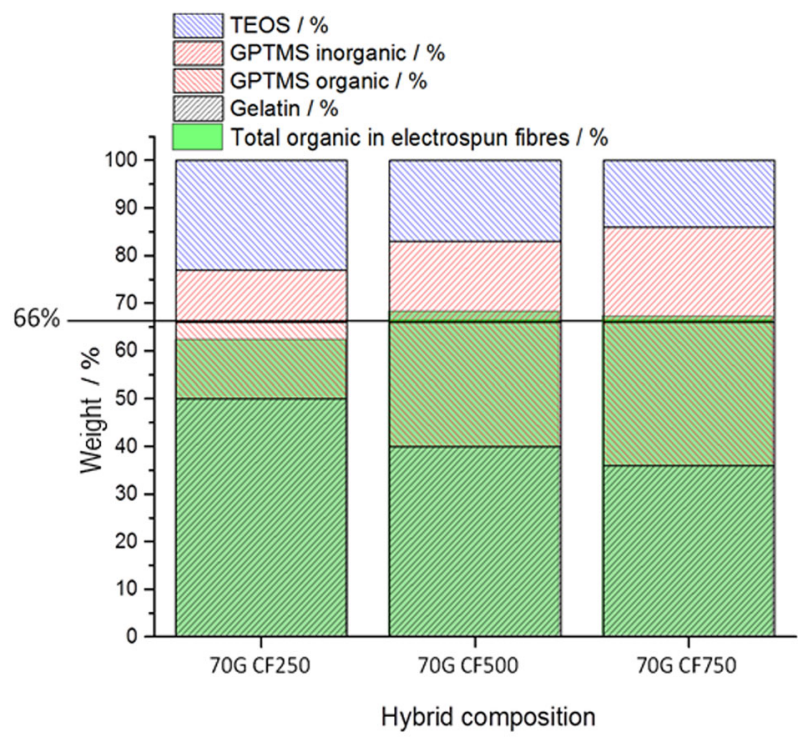

Fig. 10 Chart showing the $\mathrm{wt} \%(\mathrm{w} / \mathrm{w})$ mass contributions of gelatin, silica network from TEOS (inorganic), inorganic portion of GPTMS and organic portion of GPTMS of electrospun hybrid fibres of 70G hybrid fibres with increasing C-factor. Mean organic content is $66 \%$
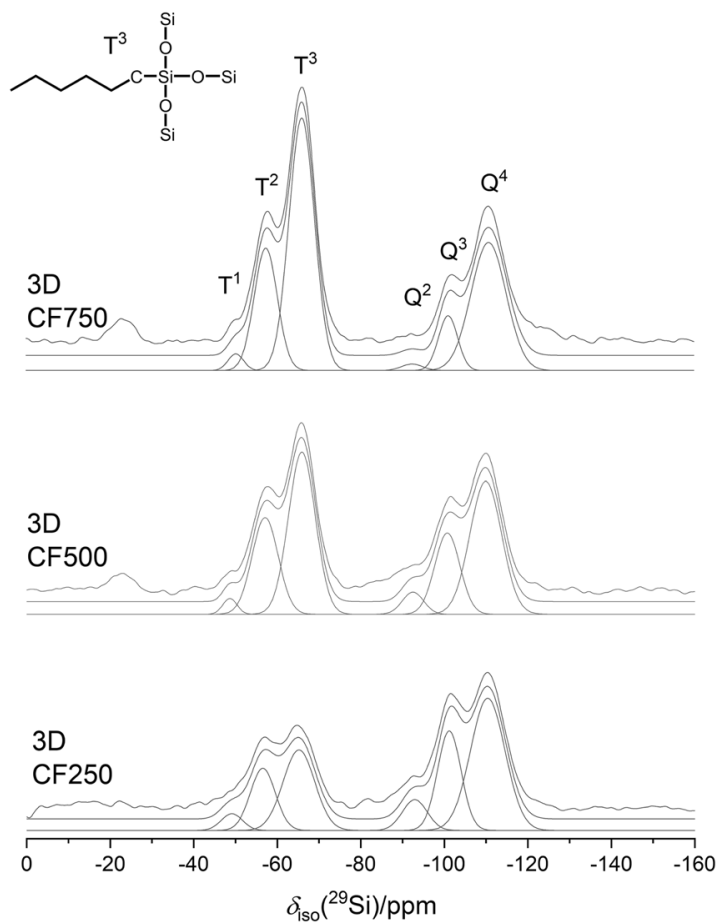

Fig. $11{ }^{29}$ Si MAS NMR data of the 3D cotton-wool electrospun $70 \mathrm{G}$ hybrids with varying C-factor: 250,500 and 750 . Each spectrum was weighted with $50 \mathrm{~Hz}$ of Lorentzian line broadening during processing and simulated using OriginPro 2019

The structural units of the hybrids were investigated by ${ }^{29} \mathrm{Si}$ MAS NMR (Fig. 11) and the degree of condensation, $D_{c}$, was calculated (Table 4). The distribution of the $\mathrm{T}$
Table 4 Results from the ${ }^{29} \mathrm{Si}$ MAS NMR data from the 3D cotton-wool electrospun 70G hybrids with varying C-factor: 250, 500 and 750: Relative intensities $(I)$ of the $T^{n}$ and $Q^{n}$ species, their assigned chemical shifts $\left(\delta_{\text {iso }}\right)$ and the resulting degree of condensation $\left(D_{c}\right)$ are given

\begin{tabular}{lllccc}
\hline & & & $\mathrm{CF} 250(3 \mathrm{D})$ & $\mathrm{CF} 500(3 \mathrm{D})$ & $\mathrm{CF} 750(3 \mathrm{D})$ \\
\hline$T^{1}$ & $\delta_{\text {iso }}$ & {$[\mathrm{ppm} \pm 0.5]$} & -49.1 & -48.6 & -50.2 \\
& $\mathrm{I}$ & {$[\% \pm 1]$} & 3 & 2 & 2 \\
$T^{2}$ & $\delta_{\text {iso }}$ & {$[\mathrm{ppm} \pm 0.5]$} & -56.5 & -57.1 & -57.5 \\
& $\mathrm{I}$ & {$[\% \pm 1]$} & 13 & 18 & 19 \\
$T^{3}$ & $\delta_{\text {iso }}$ & {$[\mathrm{ppm} \pm 0.5]$} & -65.2 & -65.9 & -66.1 \\
& $\mathrm{I}$ & {$[\% \pm 1]$} & 21 & 32 & 42 \\
$Q^{2}$ & $\delta_{\text {iso }}$ & {$[\mathrm{ppm} \pm 0.5]$} & -92.9 & -92.5 & -92.5 \\
& $\mathrm{I}$ & {$[\% \pm 1]$} & 6 & 3 & 1 \\
$Q^{3}$ & $\delta_{\text {iso }}$ & {$[\mathrm{ppm} \pm 0.5]$} & -101.2 & -100.7 & -101.1 \\
& $\mathrm{I}$ & {$[\% \pm 1]$} & 19 & 15 & 7 \\
$Q^{4}$ & $\delta_{\text {iso }}$ & {$[\mathrm{ppm} \pm 0.5]$} & -110.4 & -109.9 & -110.8 \\
& $\mathrm{I}$ & {$[\% \pm 1]$} & 38 & 30 & 30 \\
$D_{c}$ & {$[\% \pm 1]$} & 86 & 87 & 91 \\
\hline \multicolumn{2}{c}{} & & & &
\end{tabular}

species (derived from GPTMS) and Q species (derived from TEOS) for each composition was compared to identify the most condensed T structure and Q structure (Table 4). The $\mathrm{T}$ structure distribution changed the most. As expected, the contribution of the $T^{n}$ structures increased as C-factor increased and relative $Q^{n}$ was expected to decrease. For example, CF250 fibres had 21\% $T^{3}$, whereas CF750 fibres had $42 \% T^{3}$. The percentage of $T^{3}$ species increased almost linearly with $\mathrm{C}$-factor, while $\mathrm{T} 1$ and $\mathrm{T} 2$ percentages were similar. The higher percentage of higher order $\mathrm{T}$ species indicated a more condensed $\mathrm{T}$ structure in higher $\mathrm{C}$-factor hybrid fibres.

The overall $Q$ species contributions from CF250, CF500 and CF750 fibres did decrease with increasing C-factor, 63, 48 and $38 \%$, respectively; however, the $Q^{4}$ contributions decreased slightly between CF250 and CF500 from 38 to $30 \%$. Also significant was the reduction in $Q^{2}$ presence in CF750 fibres which was $1 \%$ compared to 6 and 3\% for CF250 and CF500 fibres, respectively. Therefore, CF750 fibres had the most condensed $Q$ structure as $79 \%$ of the $Q$ structure was attributed to $Q^{4}$, compared to $63 \%$ for CF500 and $56 \%$ in the CF250 hybrid fibres.

Overall, $D_{c}$ was highest for CF750 (91\%), compared to CF500 at $87 \%$ and CF250 at $86 \%$. The results agree with the FTIR (Fig. 9a) and TGA results (Fig. 10), determining that 70G CF250 fibres had the lowest connectivity, due to unreacted $\mathrm{Si}-\mathrm{OH}$. The CF500 hybrids had a high degree of coupling. CF750 had a higher $D_{c}$, than CF500, due increased coupling, but not proportional to the extra 

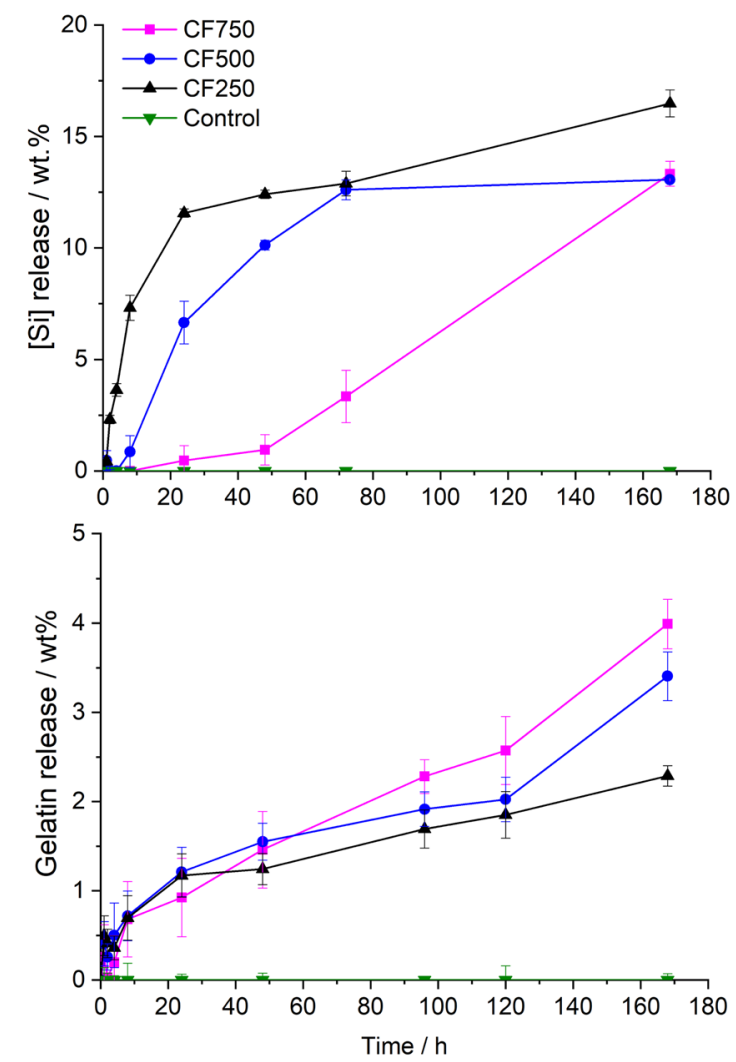

Fig. 12 Results of dissolution in TRIS for fibres made with $70 \mathrm{G}$ and CF250, 500 and 750. Over a 1-week period the Si release and gelatin release was investigated as shown in $\mathbf{a}$ and $\mathbf{b}$, respectively

GTPMS, implying excess hydrolysed GPTMS (diol) left in the hybrid.

\subsection{Dissolution}

To characterise the dissolution characteristics of the electrospun fibres, particularly whether the inorganic and organic components were released at a similar rate (congruently) as a true hybrid material, a 1-week dissolution study in TRIS solution was conducted and the release of gelatin and silicon monitored.

The silicon release showed marked differences between the different compositions (Fig. 12). CF250 hybrid fibres released $7.3 \%$ of $\mathrm{Si}$ in the first $8 \mathrm{~h}$, whereas CF500 and CF750 hybrid fibres released $<1 \mathrm{wt} \%$ of $\mathrm{Si}$. This correlated with the FTIR and solid-state NMR findings that CF250 had a high percentage of $T$ and $Q$ species in lower order (e.g., higher $T^{1}$ relative to $T^{3}$ ), compared to the hybrids of higher C-factor. After $24 \mathrm{~h}, \mathrm{CF} 250$ dissolution began to slow. CF500 showed a similar rate of release curve to CF250, however the initial rate of release for CF500 was delayed and levelling off took place at $72 \mathrm{~h}$, at a lower amount. CF750 showed a very different trend in dissolution. Instead of a rapid initial release, leading to a plateau of

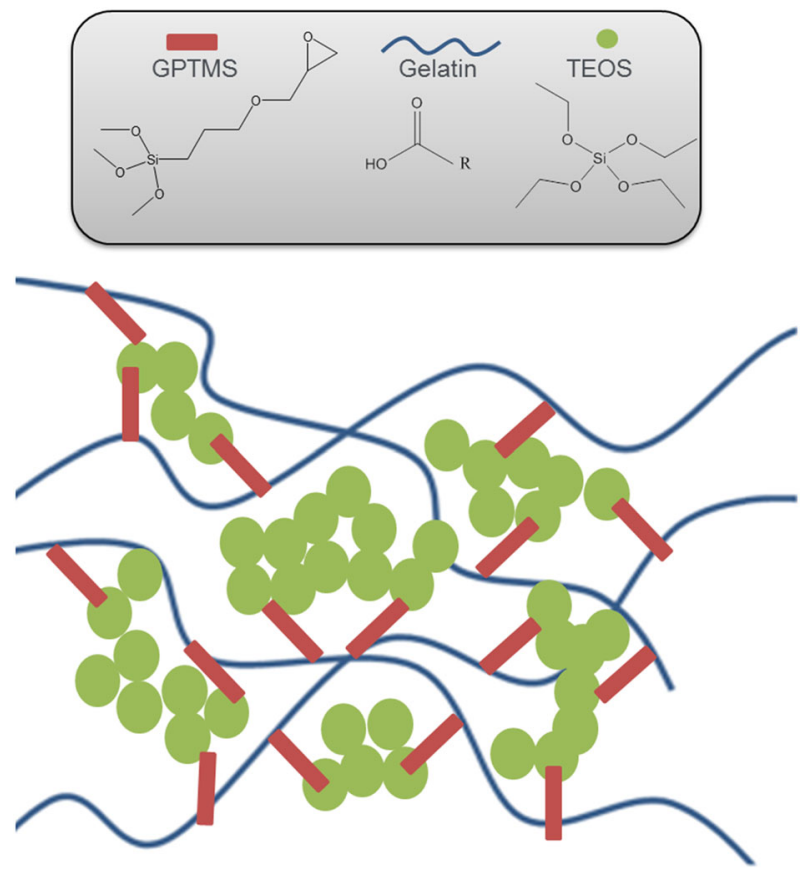

Fig. 13 Schematic of predicted hybrid structure

$\mathrm{Si}$ concentration, the release was gradual and slow, only $3.3 \mathrm{wt} \%$ of $\mathrm{Si}$ was released at $72 \mathrm{~h}$ for CF750, compared to $12.6 \mathrm{wt} \%$ for both CF500 and CF750. This correlated to the solid-state NMR results that CF750 had almost no $Q^{2}$ species, hence reducing dissolution of the silica network. At the 1-week time point, CF250 showed the highest release of $16.5 \mathrm{wt} \%$ while CF500 and CF750 were lower, $\sim 13 \mathrm{wt} \%$. The reduced soluble silica release at higher $\mathrm{C}$-factors correlates to the overall improved connectivity of the $T$ structure with increased $\mathrm{C}$-factor.

The gelatin had a similar release trend for all compositions (Fig. 12), with steady sustained release (no burst release) at early time points, and none of the fibres caused a plateau in the release by the end of 7 days. Beyond $48 \mathrm{~h}$, the amount of gelatin release seemed to increase with increasing $\mathrm{C}$ factor, but all released $<4 \mathrm{wt} \%$ of the gelatin content. The dissolution of the silicon and gelatin was less congruent compared to silica/gelatin hybrids foamed with HF catalyst [31]. This could be in part due to the higher surface area of the spun fibres, compared to foams but it could also be due to the evolution of the hybrid structure. As opposed to completely interpenetrating co-networks of silica and gelatin, it seems the gelatin molecules were cross linked via GPTMS and small clusters of silica (Fig. 13). As the silica network is broken down, $\mathrm{Si}$ is released but as the gelatin molecules are significantly larger in size and with many crosslinks, this breakdown in silica does not correspond to release of gelatin. Importantly, the release of gelatin was sustained, which is beneficial to the use of the 3D fibres as scaffolds. 


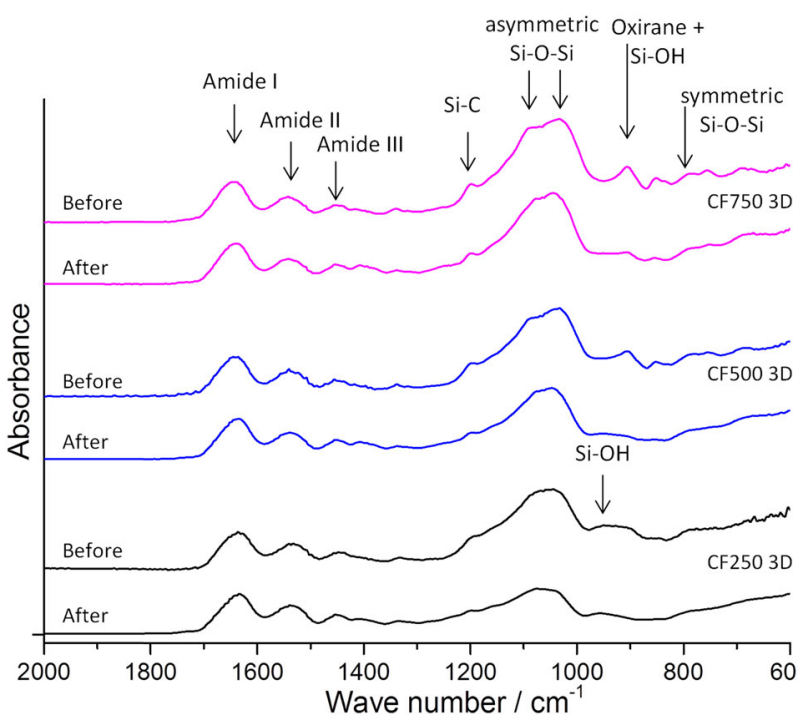

Fig. 14 FTIR spectra of 70G CF250, CF500 and CF750 fibres before and after 1-week dissolution study in TRIS (spectra were normalised to the amide I bands)

After the dissolution study, the fibres appeared softened and distorted but were not significantly smaller in diameter, due to the low gelatin release. The mean fibre diameters were $1.58 \pm 0.36,1.33 \pm 0.43$ and $1.15 \pm$ $0.48 \mu \mathrm{m}$ for CF250, CF500 and CF750, respectively. FTIR spectra of the hybrids did change after dissolution (Fig. 14). While gelatin reduced during dissolution, its release was similar for all compositions, so the data were still comparable. For all compositions, there was a reduction in the relative intensity of the $\mathrm{Si}-\mathrm{C}$ band at $1200 \mathrm{~cm}^{-1}$ and $\mathrm{Si}-\mathrm{OH} /$ oxirane band at $900 \mathrm{~cm}^{-1}$ (relative to the gelatin amide I band), indicating a loss of hydrolysed GPTMS relative to gelatin for all compositions. This could be due to cleavage of the ester bonds between the GPTMS and gelatin, which can be hydrolysed by water. The asymmetric Si-O-Si $\left(1040\right.$ and $\left.1090 \mathrm{~cm}^{-1}\right)$ bands and symmetric $\mathrm{Si}-\mathrm{O}-\mathrm{Si}$ band $\left(790 \mathrm{~cm}^{-1}\right)$ reduced for CF250 and CF500, but the reduction was less for CF750. This correlated to the solid-state NMR results, where a high proportion of well-connected GPTMS molecules and low proportion of $Q^{2}$ species were observed for CF750 hybrid fibres compared to lower C-factor fibres.

\section{Conclusions}

For silica/gelatin class-II hybrids, with a nominal gelatin to silica molar ratio of 70:30, morphology of the electrospun structure, at fixed humidity, was controlled through viscosity (solution aging time) and degree of coupling between the silica and gelatin (C-factor). Constant electrospinning parameters used were: needle-collector separation of $20 \mathrm{~cm}$, flow rate of $0.05 \mathrm{~mL} \mathrm{~min}^{-1}, 22$ gauge stainless steel needle, humidity of $55 \%$ and syringe temperature of $50{ }^{\circ} \mathrm{C}$. An applied voltage of $9.5 \mathrm{kV}$ was determined to be optimal for this hybrid system. Combinations of NMR, TGA and dissolution studies gave evidence of successful coupling, the first time this was achieved in hybrid fibres.

At the lower C-factors of CF185 and CF250, 2D fibre mats of distinct fibres were formed when sols of low viscosity $(<50 \mathrm{mPa} \mathrm{s})$ were spun. Increasing the $\mathrm{C}$-factor increased the coupling and stiffness of the fibres, which also improved their spinnability. To achieve distinct 3D fibres with high $\mathrm{C}$-factors, the first consideration was the requisite viscosity. The viscosity-sol aging time plot showed an inflection point. The onset time of the inflection point increased with $\mathrm{C}$-factor due to the increased amount of solvent present. 3D cotton-wool-like scaffolds, with discrete fibres of thickness of $\sim 1.5 \mu \mathrm{m}$, were formed when the sol was aged to the point that the viscosity started to increase sharply $(60-80 \mathrm{mPa}$ s viscosity for CF250 and CF500, 60-100 mPa s viscosity for CF750). Preventing the fibres from coming into contact with the flat surface of the collector was also key to the formation of these 3D structures. Increasing the viscosity too high can lead to fusion of the fibres. However, for low C-factor (CF185) sols, electrospinning in this stage resulted in fused, erratic non-uniform fibre formation.

The dissolution of the fibres over 1 week in TRIS solution showed sustained, rather than burst release of gelatin and increasing coupling (C-factor) decreased the dissolution of the silica. The 70G CF750 composition was the most promising composition for scaffold development as it showed slowest and most congruent dissolution in TRIS. It was also easiest to form 3D cotton-wool-like structures in the largest volumes. Increasing the $\mathrm{C}$-factor further is likely to only increase the amount of uncoupled hydrolysed GPTMS in the sol or gel, due to the limited number of carboxylic groups available for coupling on the gelatin chain. NMR results estimated the maximum C-factor to be 680 , which is recommended for future scaffold development.

Acknowledgements JVH acknowledges financial support for the solid state NMR instrumentation at Warwick used in this research, which was funded by EPSRC (grants EP/M028186/1 and EP/K024418/1), the University of Warwick, and the Birmingham Science City AM1 and AM2 projects that were supported by Advantage West Midlands (AWM) and the European Regional Development Fund (ERDF).

\section{Compliance with ethical standards}

Conflict of interest The authors declare that they have no conflict of interest. 
Publisher's note Springer Nature remains neutral with regard to jurisdictional claims in published maps and institutional affiliations.

Open Access This article is licensed under a Creative Commons Attribution 4.0 International License, which permits use, sharing, adaptation, distribution and reproduction in any medium or format, as long as you give appropriate credit to the original author(s) and the source, provide a link to the Creative Commons license, and indicate if changes were made. The images or other third party material in this article are included in the article's Creative Commons license, unless indicated otherwise in a credit line to the material. If material is not included in the article's Creative Commons license and your intended use is not permitted by statutory regulation or exceeds the permitted use, you will need to obtain permission directly from the copyright holder. To view a copy of this license, visit http://creativecommons. org/licenses/by/4.0/.

\section{References}

1. Jones JR (2013) Review of bioactive glass: from Hench to hybrids. Acta Biomater 9(1):4457-4486. https://doi.org/10.1016/j. actbio.2012.08.023

2. Oonishi H, Hench LL, Wilson J, Sugihara F, Tsuji E, Matsuura M, Kin S, Yamamoto T, Mizokawa S (2000) Quantitative comparison of bone growth behavior in granules of Bioglass (R), A-W glassceramic, and hydroxyapatite. J Biomed Mater Res 51(1):37-46

3. Baino F, Novajra G, Miguez-Pacheco V, Boccaccini AR, VitaleBrovarone C (2016) Bioactive glasses: special applications outside the skeletal system. J Non-Cryst Solids 432:15-30. https:// doi.org/10.1016/j.jnoncrysol.2015.02.015

4. Kargozar S, Hamzehlou S, Baino F (2019) Can bioactive glasses be useful to accelerate the healing of epithelial tissues?. Mater Sci Eng C 97:1009-1020. https://doi.org/10.1016/j.msec.2019.01.028

5. Lin C, Mao C, Zhang JJ, Li YL, Chen XF (2012) Healing effect of bioactive glass ointment on full-thickness skin wounds. Biomed Mater 7(4). https://doi.org/10.1088/1748-6041/7/4/045017

6. Zhao SC, Li L, Wang H, Zhang YD, Cheng XG, Zhou N, Rahaman MN, Liu ZT, Huang WH, Zhang CQ (2015) Wound dressings composed of copper-doped borate bioactive glass microfibers stimulate angiogenesis and heal full-thickness skin defects in a rodent model. Biomaterials 53:379-391. https://doi. org/10.1016/j.biomaterials.2015.02.112

7. Lin YN, Brown RF, Jung SB, Day DE (2014) Angiogenic effects of borate glass microfibers in a rodent model. J Biomed Mater Res Part A 102(12):4491-4499. https://doi.org/10.1002/ jbm.a.35120

8. Rezwan K, Chen QZ, Blaker JJ, Boccaccini AR (2006) Biodegradable and bioactive porous polymer/inorganic composite scaffolds for bone tissue engineering. Biomaterials 27(18):3413-3431. https://doi.org/10.1016/j.biomaterials.2006.01.039

9. Rhee SH, Choi JY, Kim HM (2002) Preparation of a bioactive and degradable poly(epsilon-caprolactone)/silica hybrid through a solgel method. Biomaterials 23(24):4915-4921. https://doi.org/10. 1016/s0142-9612(02)00251-x

10. Rhee SH, Lee YK, Lim BS (2004) Evaluation of a novel poly (epsilon-caprolactone)-organosiloxane hybrid material for the potential application as a bioactive and degradable bone substitute. Biomacromolecules 5(4):1575-1579

11. Connell LS, Gabrielli L, Mahony O, Russo L, Cipolla L, Jones JR (2017) Functionalizing natural polymers with alkoxysilane coupling agents: reacting 3-glycidoxypropyl trimethoxysilane with poly(gamma-glutamic acid) and gelatin. Polym Chem 8 (6):1095-1103. https://doi.org/10.1039/c6py01425a
12. Tian D, Blacher S, Pirard JP, Jerome R (1998) Biodegradable and biocompatible inorganic-organic hybrid materials. 3. A valuable route to the control of the silica porosity. Langmuir 14 (7):1905-1910

13. Vert M, Mauduit J, Li SM (1994) Biodegradation of pla/ga polymers-increasing complexity. Biomaterials 15(15):1209-1213. https://doi.org/10.1016/0142-9612(94)90271-2

14. Gabrielli L, Connell L, Russo L, Jimenez-Barbero J, Nicotra F, Cipolla L, Jones JR (2014) Exploring GPTMS reactivity against simple nucleophiles: chemistry beyond hybrid materials fabrication. RSC Adv 4(4):1841-1848. https://doi.org/10.1039/c3ra44748k

15. Novak BM (1993) Hybrid nanocomposite materials-between inorganic glasses and organic polymers. Adv Mater 5(6):422-433. https://doi.org/10.1002/adma.19930050603

16. Dieudonne X, Montouillout V, Jallot E, Fayon F, Lao J (2014) Bioactive glass hybrids: a simple route towards the gelatin- $\mathrm{SiO}_{2}-$ $\mathrm{CaO}$ system. Chem Commun 50(63):8701-8704. https://doi.org/ $10.1039 / \mathrm{c} 3 \mathrm{cc} 49113 \mathrm{~g}$

17. Lao J, Dieudonne X, Fayon F, Montouillout V, Jallot E (2016) Bioactive glass-gelatin hybrids: building scaffolds with enhanced calcium incorporation and controlled porosity for bone regeneration. J Mat Chem B 4(14):2486-2497. https://doi.org/10.1039/ c5tb02345a

18. Ren L, Tsuru K, Hayakawa S, Osaka A (2002) Novel approach to fabricate porous gelatin-siloxane hybrids for bone tissue engineering. Biomaterials 23(24):4765-4773

19. Panzavolta S, Gioffre M, Focarete ML, Gualandi C, Foroni L, Bigi A (2011) Electrospun gelatin nanofibers: optimization of genipin cross-linking to preserve fiber morphology after exposure to water. Acta Biomaterialia 7(4):1702-1709. https://doi.org/10. 1016/j.actbio.2010.11.021

20. Skotak M, Noriega S, Larsen G, Subramanian A (2010) Electrospun cross-linked gelatin fibers with controlled diameter: the effect of matrix stiffness on proliferative and biosynthetic activity of chondrocytes cultured in vitro. J Biomed Mater Res Part A 95A (3):828-836. https://doi.org/10.1002/jbm.a.32850

21. Richard A, Margaritis A (2001) Poly(glutamic acid) for biomedical applications. Crit Rev Biotechnol 21(4):219-232. https://doi. org/10.1080/07388550108984171

22. Poologasundarampillai G, Ionescu C, Tsigkou O, Murugesan M, Hill RG, Stevens MM, Hanna JV, Smith ME, Jones JR (2010) Synthesis of bioactive class II poly(gamma-glutamic acid)/silica hybrids for bone regeneration. J Mater Chem 20(40):8952-8961. https://doi.org/10.1039/c0jm00930j

23. Poologasundarampillai G, Yu B, Tsigkou O, Valliant EM, Yue S, Lee PD, Hamilton RW, Stevens MM, Kasuga T, Jones JR (2012) Bioactive silica-poly(g-glutamic acid) hybrids for bone regeneration: effect of covalent coupling on dissolution and mechanical properties and fabrication of porous scaffolds. Soft Matter 8 (17):4822-4832. https://doi.org/10.1039/c2sm00033d

24. Poologasundarampillai G, Yu B, Tsigkou O, Wang D, Romer F, Bhakhri V, Giuliani F, Stevens MM, McPhail DS, Smith ME, Hanna JV, Jones JR (2014) Poly(gamma-glutamic acid)/silica hybrids with calcium incorporated in the silica network by use of a calcium alkoxide precursor. Chem Eur J 20(26):8149-8160

25. Valliant EM, Romer F, Wang D, McPhail DS, Smith ME, Hanna JV, Jones JR (2013) Bioactivity in silica/poly(gamma-glutamic acid) sol-gel hybrids through calcium chelation. Acta Biomater 9 (8):7662-7671. https://doi.org/10.1016/j.actbio.2013.04.037

26. Shirosaki Y, Okayama T, Tsuru K, Hayakawa S, Osaka A (2008) Synthesis and cytocompatibility of porous chitosan-silicate hybrids for tissue engineering scaffold application. Chem Eng $\mathrm{J}$ 137(1):122-128. https://doi.org/10.1016/j.cej.2007.10.012

27. Shirosaki Y, Tsuru K, Moribayashi H, Hayakawa S, Nakamura Y, Gibson IR, Osaka A (2010) Preparation of osteocompatible Si 
(IV)-enriched chitosan-silicate hybrids. J Ceram Soc Jpn 118 (1383):989-992. https://doi.org/10.2109/jcersj2.118.989

28. Wang DM, Romer F, Connell L, Walter C, Saiz E, Yue S, Lee PD, McPhail DS, Hanna JV, Jones JR (2015) Highly flexible silica/chitosan hybrid scaffolds with oriented pores for tissue regeneration. J Mat Chem B 3(38):7560-7576. https://doi.org/10. 1039/c5tb00767d

29. Connell LS, Romer F, Suarez M, Valliant EM, Zhang ZY, Lee PD, Smith ME, Hanna JV, Jones JR (2014) Chemical characterisation and fabrication of chitosan-silica hybrid scaffolds with 3glycidoxypropyl trimethoxysilane. J Mat Chem B 2(6):668-680. https://doi.org/10.1039/c3tb21507e

30. Pereira MM, Jones JR, Orefice RL, Hench LL (2005) Preparation of bioactive glass-polyvinyl alcohol hybrid foams by the sol-gel method. J Mater Sci Mater Med 16(11):1045-1050

31. Mahony O, Tsigkou O, Ionescu C, Minelli C, Ling L, Hanly R, Smith ME, Stevens MM, Jones JR (2010) Silica-gelatin hybrids with tailorable degradation and mechanical properties for tissue regeneration. Adv Funct Mater 20(22):3835-3845. https://doi.org/ 10.1002/adfm.201000838

32. Mahony O, Yue S, Ionescu C, Hanna JV, Smith ME, Lee PD, Jones JR (2014) Silica-gelatin hybrids for tissue regeneration: inter-relationships between the process variables. J Sol-Gel Sci Technol 69(2):288-298

33. Gao C, Rahaman MN, Gao Q, Teramoto A, Abe K (2013) Robotic deposition and in vitro characterization of $3 \mathrm{D}$ gelatinbioactive glass hybrid scaffolds for biomedical applications. J Biomed Mater Res Part A 101(7):2027-2037. https://doi.org/10.1002/jbm. a.34496

34. Tallia F, Russo L, Li S, Orrin ALH, Shi X, Chen S, Steele JAM, Meille S, Chevalier J, Lee PD, Stevens MM, Cipolla L, Jones JR (2018) Bouncing and 3D printable hybrids with self-healing properties. Mater Horiz 5:849

35. Li S, Tallia F, Mohammed AA, Stevens MM, Jones JR (2020) Scaffold channel size influences stem cell differentiation pathway in 3-D printed silica hybrid scaffolds for cartilage regeneration. Biomater Sci. https://doi.org/10.1039/C9BM01829H

36. McCullen SD, Autefage H, Callanan A, Gentleman E, Stevens MM (2012) Anisotropic fibrous scaffolds for articular cartilage regeneration. Tissue Eng Part A 18(19-20):2073-2083. https:// doi.org/10.1089/ten.tea.2011.0606

37. Steele JAM, McCullen SD, Callanan A, Autefage H, Accardi MA, Dini D, Stevens MM (2014) Combinatorial scaffold morphologies for zonal articular cartilage engineering. Acta Biomater 10 (5):2065-2075. https://doi.org/10.1016/j.actbio.2013.12.030

38. Li D, Xia YN (2004) Electrospinning of nanofibers: Reinventing the wheel? Adv Mater 16(14):1151-1170. https://doi.org/10. 1002/adma.200400719

39. Shao CL, Kim HY, Gong J, Ding B, Lee DR, Park SJ (2003) Fiber mats of poly(vinyl alcohol)/silica composite via electrospinning. Mater Lett 57(9-10):1579-1584. https://doi.org/10.1016/s0167$577 \mathrm{x}(02) 01036-4$

40. Rhee SH (2004) Bone-like apatite-forming ability and mechanical properties of poly(epsilon-caprolactone)/silica hybrid as a function of poly(epsilon-caprolactone) content. Biomaterials 25(7-8):1167-1175. https://doi.org/10.1016/j.biomaterials.2003.08.004

41. Poologasundarampillai G, Wang D, Li S, Nakamura J, Bradley R, Lee PD, Stevens MM, McPhail DS, Kasuga T, Jones JR (2014) Cotton-wool-like bioactive glasses for bone regeneration. Acta Biomater 10(8):3733-3746. https://doi.org/10.1016/j.actbio.2014.05.020

42. Norris E, Ramos-Rivera C, Poologasundarampillai G, Clark JP, Ju Q, Obata A, Hanna JV, Kasuga T, Mitchell CA, Jell G, Jones JR (2020) Electrospinning 3D bioactive glasses for wound healing. Biomed Mater 15(1):14. https://doi.org/10.1088/1748-605X/ab591d

43. Obata A, Ozasa H, Kasuga T, Jones JR (2013) Cotton woollike poly(lactic acid)/vaterite composite scaffolds releasing soluble silica for bone tissue engineering. J Mater Sci-Mater Med 24(7):1649-1658. https://doi.org/10.1007/s10856-0134930-5

44. Kasuga T, Obata A, Maeda H, Ota Y, Yao X, Oribe K (2012) Siloxane-poly(lactic acid)-vaterite composites with 3D cotton-like structure. J Mater Sci-Mater Med 23(10):2349-2357. https://doi. org/10.1007/s10856-012-4607-5

45. Gao CX, Ito S, Obata A, Mizuno T, Jones JR, Kasuga T (2016) Fabrication and in vitro characterization of electrospun poly (gamma-glutamic acid)-silica hybrid scaffolds for bone regeneration. Polymer 91:106-117. https://doi.org/10.1016/j.polymer. 2016.03.056

46. Gao CX, Gao Q, Li YD, Rahaman MN, Teramoto A, Abe K (2013) In vitro evaluation of electrospun gelatin-bioactive glass hybrid scaffolds for bone regeneration. J Appl Polym Sci 127 (4):2588-2599. https://doi.org/10.1002/app.37946

47. Yao YH, Shen LL, Wei AL, Wang TL, Chen S (2019) Facile synthesis, microstructure, photo-catalytic activity, and antibacterial property of the novel Ag@gelatin-silica hybrid nanofiber membranes. J Sol-Gel Sci Technol 89(3):651-662. https://doi. org/10.1007/s10971-018-04914-Z

48. Gabrielli L, Russo L, Poveda A, Jones JR, Nicotra F, JimenezBarbero J, Cipolla L (2013) Epoxide opening versus silica condensation during sol-gel hybrid biomaterial synthesis. Chem Eur J 19(24):7856-7864. https://doi.org/10.1002/chem. 201204326

49. Song J-H, Kim H-E, Kim H-W (2008) Production of electrospun gelatin nanofiber by water-based co-solvent approach. J Mater Sci-Mater Med 19(1):95-102. https://doi.org/10.1007/s10856007-3169-4

50. Chen H-C, Jao W-C, Yang M-C (2009) Characterization of gelatin nanofibers electrospun using ethanol/formic acid/water as a solvent. Polym Adv Technol 20(2):98-103. https://doi.org/10. 1002/pat. 1244

51. Fong H, Chun I, Reneker DH (1999) Beaded nanofibers formed during electrospinning. Polymer 40(16):4585-4592. https://doi. org/10.1016/s0032-3861(99)00068-3

52. Song JH, Yoon BH, Kim HE, Kim HW (2008) Bioactive and degradable hybridized nanofibers of gelatin-siloxane for bone regeneration. J Biomed Mater Res Part A 84A(4):875-884. https:// doi.org/10.1002/jbm.a.31330

53. De Vrieze S, Van Camp T, Nelvig A, Hagstrom B, Westbroek P, De Clerck K (2009) The effect of temperature and humidity on electrospinning. J Mater Sci 44(5):1357-1362. https://doi.org/10. 1007/s10853-008-3010-6

54. Harris RK, Becker ED, de Menezes SMC, Goodfellow R, Granger $P$ (2002) NMR nomenclature: nuclear spin properties and conventions for chemical shifts-IUPAC recommendations 2001 (Reprinted from Pure Appl. Chem, vol 73, pg 1795-1818, 2001). Solid State Nucl Magn Reson 22(4):458-483. https://doi.org/10. 1006/snmr.2002.0063

55. Maçon ALB, Kim TB, Valliant EM, Goetschius K, Brow RK, Day DE, Hoppe A, Boccaccini AR, Kim IY, Ohtsuki C, Kokubo T, Osaka A, Vallet-Regí M, Arcos D, Fraile L, Salinas AJ, Teixeira AV, Vueva Y, Almeida RM, Miola M, Vitale-Brovarone C, Verné E, Höland W, Jones JR (2015) A unified in vitro evaluation for apatite-forming ability of bioactive glasses and their variants. J Mater Sci: Mater Med 26(2):115. https://doi.org/10.1007/s10856015-5403-9

56. Xie J, Bao M, Bruekers SMC, Huck WTS (2017) Collagen gels with different fibrillar microarchitectures elicit different cellular responses. ACS Appl Mater Inter 9(23):19630-19637. https://doi. org/10.1021/acsami.7b03883

57. Bhardwaj N, Kundu SC (2010) Electrospinning: a fascinating fiber fabrication technique. Biotechnol Adv 28(3):325-347. https://doi.org/10.1016/j.biotechadv.2010.01.004 
58. Hohman MM, Shin M, Rutledge G, Brenner MP (2001) Electrospinning and electrically forced jets. II. Appl Phys Fluids 13 (8):2221-2236. https://doi.org/10.1063/1.1384013

59. Zhang CX, Yuan XY, Wu LL, Han Y, Sheng J (2005) Study on morphology of electrospun poly(vinyl alcohol) mats. Eur Polym $\mathbf{J}$ 41(3):423-432. https://doi.org/10.1016/j.eurpolymj.2004.10.027
60. Ki CS, Baek DH, Gang KD, Lee KH, Um IC, Park YH (2005) Characterization of gelatin nanofiber prepared from gelatin-formic acid solution. Polymer 46(14):5094-5102. https://doi.org/10. 1016/j.polymer.2005.04.040

61. Dusek K (1971) Phase separation in ternary systems induced by crosslinking. Chemicke Zvesti 25(3):184 